\title{
The non-evaginated secondary prosencephalon of vertebrates
}

\section{Nerea Moreno* and Agustín González}

Departamento de Biología Celular, Facultad de Biología, Universidad Complutense of Madrid, Madrid, Spain

\section{Edited by:}

Fernando Martinez-Garcia, Universidad de Valencia, Spain

\section{Reviewed by:}

Glenn R. Northcutt, University of

California, USA

Sylvie Retaux, CNRS, France

${ }^{*}$ Correspondence:

Nerea Moreno, Facultad de Biología, Departamento de Biología Celular,

Universidad Complutense, Calle José Antonio Novais 2, 28040 Madrid,

Spain.

e-mail:nerea@bio.ucm.es
The secondary prosencephalon (telencephalon plus hypothalamus) is probably the most complex area of the brain, with complicated patterning specifications. As yet, no prosomeric subdivisions have been reported and only distinct histogenetic territories have been recognized. In the present comparative study we analyzed cross-correlated expression maps in the nonevaginated territories of the secondary prosencephalon in different vertebrates throughout development, to assess the existence of comparable divisions and subdivisions in the different groups. Each division is characterized by expression of a unique combination of developmental regulatory genes, and each appears to represent a self-regulated and topologically constant histogenetic brain compartment that gives rise to a specific cell group. The non-evaginated area of the telencephalon corresponds to the preoptic region, whereas the hypothalamus, topologically rostral to the diencephalic prethalamus, includes basal (mammillary and tuberal) and alar (paraventricular and suprachiasmatic) parts. This complex area is specified by a cascade of transcription factors, among which the Dlx family members and Nkx2.1 are essential for the correct development. The only exception is found in the subdivision named termed the supraoptoparaventricular area, in which the transcription factor Orthopedia is essential in restricting the fate of multiple categories of neuroendocrine neurons, in the absence of the D|x/

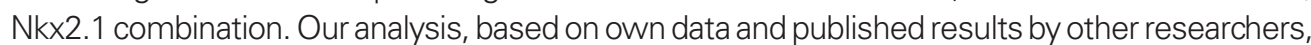
suggests that common features are shared at least by all tetrapods and, therefore, they most likely were present in the stem tetrapods. The available data for agnathans (lampreys) and other fish groups indicate that not all subdivisions of the secondary prosencephalon were present at the origin of vertebrates, raising important questions about their evolution.

Keywords: preoptic area, hypothalamus, development, homology, tetrapods

\section{THE NON-EVAGINATED SECONDARY PROSENCEPHALON}

Developmental processes occurring from the neural plate stages and leading to the identification of all main brain regions entail dramatic changes, including a pronounced cephalic flexure. As the anterior neural tube closes, the embryonic brain subdivides into three primary vesicles: the rhombencephalon, the mesencephalon, and the prosencephalon, from caudal to rostral. Subsequently, the primary prosencephalon subdivides into two major components, the caudal diencephalon and the rostral secondary prosencephalon. The secondary prosencephalon constitutes the entire prechordal (rostralmost) portion of the neural tube, which gives rise to the hypothalamus ventrally, the eye vesicles dorsolaterally, the telencephalic vesicles dorsally, and a ventral telencephalic preoptic area (POA; reviewed in García-López et al., 2009; Vieira et al., 2010). Like the caudal vesicles, the secondary prosencephalon is formed by alar and basal derivatives. Thus, the hypothalamus includes alar and basal plate components, whereas the eye field and the telencephalon are completely derived from the alar region (Figure 1). The topological arrangement of these forebrain subdivisions is a consequence of the location of their primordia in the neural plate (Couly and Le Douarin, 1987; Eagleson and Harris, 1990; Rubenstein et al., 1998; Inoue et al., 2000; GarcíaLópez et al., 2009; Vieira et al., 2010). The mechanisms leading to the formation of the prosencephalon and its subsequent patterning are highly conserved in evolution, especially the genetic codes that result in the production of forebrain subdivisions recognized along the rostrocaudal and dorsoventral axes in different vertebrates.
Apart from the evaginated telencephalic and eye vesicles, the rest of the secondary prosencephalon (here referred to as the non-evaginated secondary prosencephalon, regardless the diverse evaginations that may occur in the hypothalamus) has been traditionally considered as the ventral portion of the diencephalon. In particular, the term hypothalamus (hypo from the old Greek ÿpó: under) literally describes its topographical position beneath the thalamus. Thus, in the literature, frequent definitions describe the preoptic region $(\mathrm{PO})$ and the hypothalamus proper as special regions of the ventral diencephalon that are involved in regulation of the endocrine system, the autonomic nervous system, and related brain systems (Bruce, 2008; Hodos, 2008). These definitions, older or current, treat the brain as a column, so that a transverse section of an adult brain shows the hypothalamus beneath the thalamus, and molecular and developmental data are not taken into account. However, detailed comparison of diverse developmental gene expression patterns gathered in the last decades led Puelles and Rubenstein to postulate in 1993 the prosomeric model, modified 10 years later (Puelles and Rubenstein, 1993, 2003) as a morphological framework (paradigm), which divides the forebrain into transverse segments (prosomeres) and longitudinal zones. In this prosomeric context, we refer in the present analysis to the non-evaginated portion of the secondary prosencephalon, only with the intention to use a short name that includes the hypothalamus and the $\mathrm{PO}$ of the telencephalon. Classically, the PO has been considered part of the hypothalamus (for review Butler and 
Hodos, 2005), but in recent years this view has changed and the PO been considered part of the telencephalon, due to its topological position in the neural plate and its genetic specification (Flames et al., 2007; García-López et al., 2008; Sánchez-Arrones et al., 2009). Therefore, in the present analysis of the PO and hypothalamus we pay special attention to the boundaries between them in diverse vertebrate species in order to gain a better understanding of the evolution of these forebrain regions.

The regions under analysis are very complex in terms of genetic specification, morphological, hodological and neurochemical organization, and, especially, function (for review see ten Donkelaar, 1998; Butler and Hodos, 2005; Medina, 2008). However, it is interesting to note that in the last years, numerous data have shown conserved patterns in the evolution of vertebrates related to the embryological origin, cell types, neurochemical organization, hodology, and functional implications of the subregions in the secondary prosencephalon (reviewed in Medina, 2008; Moreno et al., 2009). In addition, it has been increasingly reported that in these regions many differences can also be observed among vertebrates, which may reflect not only the existence of divergent evolution in the different lineages but also secondary adaptations of each group. Moreover, to this complex evolutionary equation has to be added a high divergence of sizes, shapes, and complexity of centers related to sophisticated behaviors like human consciousness, songbird vocalization, electrical responses in some fishes, etc.

In this evolutionary context, when one accomplishes a comparative analysis the main aim is to establish homologous relationships. To this end, however, many different characteristics can be considered, which sometimes make this comparison extremely difficult and dense. At least in the last years, most comparative studies of the forebrain in different vertebrates have been framed within the prosomeric model as a paradigm to interpret the results (Puelles and Rubenstein, 2003). Those studies suggest that some characteristics are more important than others in this analysis, as they determine the topology of the neural plate, the genetic specification of a topographic domain in the neural tube, the histogenetic pattern, the neuronal differentiation, hodology and, finally, neuronal organization.

With these ideas in mind, the most convenient approach to establishing homologies is to assess the number of shared features, keeping in mind that homologous structures with common morphogenetic origin may have varied enormously in the course of evolution.

\section{PATTERNING AND NEURAL SPECIFICATION}

Substantial data reported in the last years have demonstrated that the combined expression of regulatory genes is very conserved in the evolution (Puelles and Rubenstein, 1993, 2003; Bachy et al., 2001, 2002; González et al., 2002a,b; Brox et al., 2003; Moreno et al., 2004, 2005, 2008a,b, 2010; Osorio et al., 2005, 2006; Flames et al., 2007; García-López et al., 2008; Abellán and Medina, 2009; González and Northcutt, 2009; Domínguez et al., 2010), suggesting that the molecular specifications unravel the morphogenetic field formation. When comparing across species, two main concepts are to be kept in mind, "developmental regulatory genes" and "basic histogenetic domains." Both concepts allow and help explain forebrain organization in the comparative approach.
In mammals, hypothalamic neurogenesis occurs in individual nuclei between embryonic day 10 (E10) and E16 in mice (Shimada and Nakamura, 1973; Shimogori et al., 2010). Numerous studies have identified many transcription factors that regulate the development of specific hypothalamic nuclei and neuronal subtypes (Schonemann et al., 1995; Labosky et al., 1997; Wehr et al., 1997; Michaud et al., 1998; Acampora et al., 1999; Davis et al., 2004; Goshu et al., 2004; Zhao et al., 2008; Szábo et al., 2009).

In general morphological terms, seeking terminological continuity, in the prosomeric model the hypothalamus constitutes the "rostral diencephalon" (Puelles and Rubenstein, 2003). It includes alar and basal components, while the eye field and the telencephalon are exclusively derived from the alar region. The alar portion, includes the suprachiasmatic (SC) and the supraopticparaventricular (SPV) regions, which will give rise their respective hypothalamic nuclei. The basal hypothalamus includes the tuberal hypothalamus, which contains among other structures, the ventromedial nucleus, the arcuate nucleus, and the mammillary hypothalamic region, which includes the subthalamic nucleus (reviewed in Medina, 2008).

In molecular terms, Shh is essential for the specification of the hypothalamus (Chiang et al., 1996; Szábo et al., 2009) through the action, among others, of the homeobox gene Nkx2.1, whose expression is triggered by prechordal Shh signals (Kimura et al., 1996). In addition, in mammalian forebrains, $\mathrm{Nkx} 2.1$ is expressed in the basal telencephalon- POA and the basal hypothalamus (Price et al., 1992), which is severely malformed and reduced in size in knockout mice (Kimura et al., 1996; Sussel et al., 1999; Marín et al., 2002). Specially, the neural Shh has a very important and specific role in the development of the lateral hypothalamus, possibly mediated by regulation of Dlx2, Dbx1, and FoxD. The lack of Shh expression in the hypothalamic neuroepithelium results in a very reduced lateral hypothalamus, in which some of the most functionally important and characteristic neuronal subpopulations are either very reduced or completely missing, whereas the POA and the SC nucleus show normal development (Szábo et al., 2009). The transcription factor Orthopedia (Otp) is expressed in the SPV of the alar hypothalamus, the arcuate nucleus, and the oblique perimammillary band (Simeone et al., 1994; Puelles and Rubenstein, 2003; Del Giacco et al., 2006; Bardet et al., 2008), where it operates in the proper differentiation of several neurohormone-secreting nuclei (Acampora et al., 1999; Wang and Lufkin, 2000; Michaud, 2001; Eaton and Glasgow, 2007; Blechman et al., 2007; Ryu et al., 2007; Eaton et al., 2008). Otp also contributes to progenitor cell proliferation, survival, and migration (Goshu et al., 2004). The transcription factor Sim1, in parallel to Otp, acts to differentiate a large population of neurohormone- containing cells (Michaud et al., 1998; Acampora et al., 1999; Wang and Lufkin, 2000; Goshu et al., 2004). In Otp, and Sim 1 mutants, the prospective SPV cells are born and specified, but the cells do not terminally differentiate to express neuroendocrine hormone genes.

In terms of anatomical subdivisions the POA, which was previously believed to be derived from the ventral diencephalon, is currently regarded as derived from the Foxg1-positive telencephalic neuroepithelium (Zhao et al., 2008; Roth et al., 2010), whereas the hypothalamus can be subdivided into the Sim1-positive anterodorsal hypothalamic neuroepithelium, which contain the primordium of the paraventricular nucleus, and the Nkx2.1-positive 
posteroventral hypothalamic neuroepithelium, which contains the primordia of the arcuate nucleus and the ventromedial hypothalamic region, the premammillary neuroepithelium, and the mammillary neuroepithelium (reviewed in Medina, 2008; Zhao et al., 2008; Szábo et al., 2009; Shimogori et al., 2010). In terms of boundaries, the rostral hypothalamus correlates topographically with the early expression of Six3, which extends from the septum to the neurohypophysis. The boundary between the caudal hypothalamus and P3 is well defined by the expression of several genes. In the alar plate, it coincides with the sharp caudal limit of the Sim1, Otp, and Brn2 genes, which are expressed in the SPV, and with the sharp rostral limit of Arx, Dlx, and Pax6 transcripts in P3. Finally, a territorial boundary between the telencephalon and the hypothalamus has been recently defined and called the preoptohypothalamic boundary (POH; Bardet et al., 2006; Flames et al., 2007). It is delimited between the PO in the subpallium and the SPV of the hypothalamus and occupies the region just outside the Nkx2.1- and Shh-expressing POA and it also lies within the contiguous thin corridor, expressing only Dlx 5 among the studied subpallial markers (Bardet et al., 2006).

To summarize, in mammals, Shh and Nkx2.1 are expressed in the entire non-evaginated prosencephalon, with the exception of the alar hypothalamus (reviewed in Medina, 2008). The absence of Nkx2.1 expression in the alar hypothalamus in mice correlates well with the absence of Lhx6 or Lhx7 expression in this area (Rétaux et al., 1999). In the alar hypothalamus, the SPV also contains an important population of Otp-expressing cells (Bardet et al., 2008).

\section{EVOLUTIONARY TRAITS}

In modern classification schemes, living vertebrates consist of two main groups, the jawless Agnatha (represented by hagfishes and lampreys) and the jawed Gnathostomata. Jawed vertebrates are divided again into two groups, the cartilaginous Chondrichthyes (represented by sharks, rays, and chimeras) and the bony Osteichthyes. The two main groups of bony vertebrates are the ray-finned fishes (Actinopterygii) and the lobe-limbed vertebrates (Sarcopterygii). The latter comprises three groups: coelacanths (Actinistia), lungfishes (Dipnoi), and limbed vertebrates, or Tetrapoda, encompassing amphibians, reptiles, birds, and mammals (Clack, 2002).

In recent years, evolutionary/developmental studies have revealed a segmentary pattern in the developing forebrain of all the vertebrates analyzed. In this kind of comparative analysis it is essential to consider the highest possible number of groups, especially those with crucial evolutionary positions. In particular, the phylogenetic position of reptiles, especially turtles, makes their study interesting because they are purported to be the most closely related to the extinct therapsids from which mammals arose (Northcutt, 1970) but, alternatively, they have been considered the sister group to crocodiles and birds (Zardoya and Meyer, 2001a,b). It is also essential to consider amphibians in analyzing ancestral brain organization, because they constitute the only group of tetrapod anamniotes and represent a key model in the anamniote/amniote transition, as they show shared features with other tetrapods (amniotes) and also shared features with fishes (anamniotes). In the context of this transition, the colonization of land by tetrapod ancestors is presumably one of the evolutionary events that could entail more neural changes. Molecular phylogenetic research addressing this transition and the most recent paleontological evidence, suggest that lungfishes are closest living relatives of tetrapods and that several of the features defining this group were highly conserved throughout the entire evolutionary history of land vertebrates (Meyer and Wilson, 1990; Meyer and Dolven, 1992; Hedges et al., 1993; Zardoya et al., 1998; Tohyama et al., 2000; Brinkmann et al., 2004a,b; Takezaki et al., 2004; Hallstrom and Janke, 2009), making this group of fishes of particular interest in comparative studies. And finally, lampreys are jawless vertebrates, belonging to the Agnatha, the sister group of gnathostome vertebrates. Their phylogenetic position makes them an invaluable model in the study of evolutionary developmental biology, as they allow us to gain new insights into ancestral characters in vertebrates, and they also help to reveal, but also to understand the emergence of novelties at important evolutionary transitions, such as the agnathan/gnathostome transition (Kuratani et al., 2002).

According to the rationale outlined above, the evolutionary analysis of transcription factors involved in the patterning of the non-evaginated secondary prosencephalon in key vertebrate groups would be of special interest for understanding its evolution (Figures 2 and 3 ). In recent years, cell groups and regions that were characterized according to gene expression patterns in the prosencephalon of mammals have been similarly analyzed in the brains of multiple vertebrates (Figures 2 and 3; Puelles and Rubenstein, 1993, 2003; Bachy et al., 2001, 2002; González et al., 2002a,b; Brox et al., 2003; Moreno et al., 2004, 2005, 2008a,b, 2010; Osorio et al., 2005, 2006; Flames et al., 2007; García-López et al., 2008; Abellán and Medina, 2009; Domínguez et al., 2010). These cell groups and regions in the secondary prosencephalon, and many of their neurochemical and connectional features, appear to be highly conserved in the evolution of tetrapods, since these features show similarities from amphibians through mammals (for review see Reiner et al., 1998; Marín et al., 1998; ten Donkelar, 1998; Moreno et al., 2009). Nevertheless, although many characteristics are shared, the degree of complexity increases during evolution from the common ancestor of tetrapods to birds and mammals.

Current theories regarding the organization of the forebrain in mammals consider that the subpallium encompasses the non-evaginated telencephalon, anterior (topologically dorsal) to the optic chiasm (see Figure 1; Flames et al., 2007; García-López et al., 2008). It is composed of the $\mathrm{PO}$, which contains the commissural preoptic division (POC) and the POA proper, which is located at the base of (topologically rostral to) the former (for review see Moreno et al., 2009); both express Nkx2.1 and Shh in the ventricular layer during development. In chicks, the PO has been similarly recognized as a part of the subpallium and is characterized by the expression of both Nkx2.1 and Shh (Abellán and Medina, 2009). In addition to the distinct expression of Shh, the PO is also distinguished from the subpallial pallidal division (derived from the medial ganglionic eminence, MGE) by its expression of Islet1 (Abellán and Medina, 2009). The PO in birds is also said to contain the two major subdivisions: the commissural POA, comparable to the same-named subdivision in mice (pPO1 of Flames et al., 2007; POC of GarcíaLópez et al., 2008) and characterized by strong expression of Shh and Lhx7 and by its relation to the anterior commissure; and a basal POA, comparable to the ventral preoptic subdivision ( $\mathrm{pPO} 2$ of Flames et al. (2007; POv of García-López et al., 2008). In the 
vertebrates analyzed in our laboratory (Figures $2 \mathrm{~A}-\mathbf{F}$ ), the situation in mice and chicks largely agrees with the results obtained in the PO of Pseudemy scripta (Moreno et al., 2010), Xenopus laevis (Moreno et al., 2008a; Domínguez et al., 2010), and the lungfishes Protopterus dolloi and Neoceratodus forsteri (unpublished observations). We identified the PO (Figures 2A-C) and the POC (Figures 2D-E) by the expression of Shh, Nkx2.1, Lhx7, and Isl1 and the absence of Tbr1 and Pax6 (Moreno et al., 2004, 2008a; 2010; Domínguez et al., 2010). In teleost fishes (including zebrafish), Shh is expressed in a small subdivision of the Nkx2.1-expressing domain of the basal telencephalon (Rohr et al., 2001; Scholpp et al., 2006; Menuet et al., 2007), suggesting that the subpallium of early jawed vertebrates likely included striatal, pallidal, and preoptic subdivisions. The existence of pallidal and preoptic domains in the subpallium

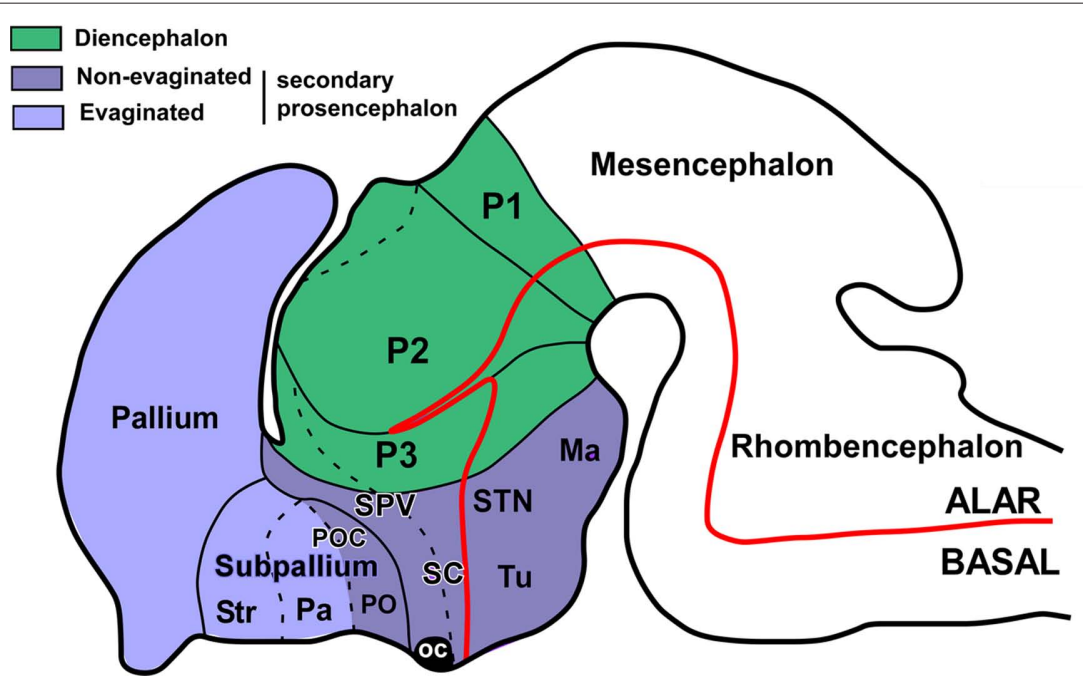

FIGURE 1 |The secondary prosencephalon in mammals. Schematic drawing of a lateral view of the brain showing the main subdivisions of the prosencephalon, as currently accepted. The dotted lines indicated subdivisions in the same domain. Ma, mammillary area; oc, optic chiasm; P1-3, prosomeres 1-3; $\mathrm{Pa}$, pallidum; $\mathrm{PO}$, preoptic region; $\mathrm{POC}$, commissural preoptic area; SC, suprachiasmatic area; SPV, supraopticparaventricular area; STN, subthalamic nucleus; Str, striatum; Tu, tuberal hypothalamus. (Modified from Medina, 2008).
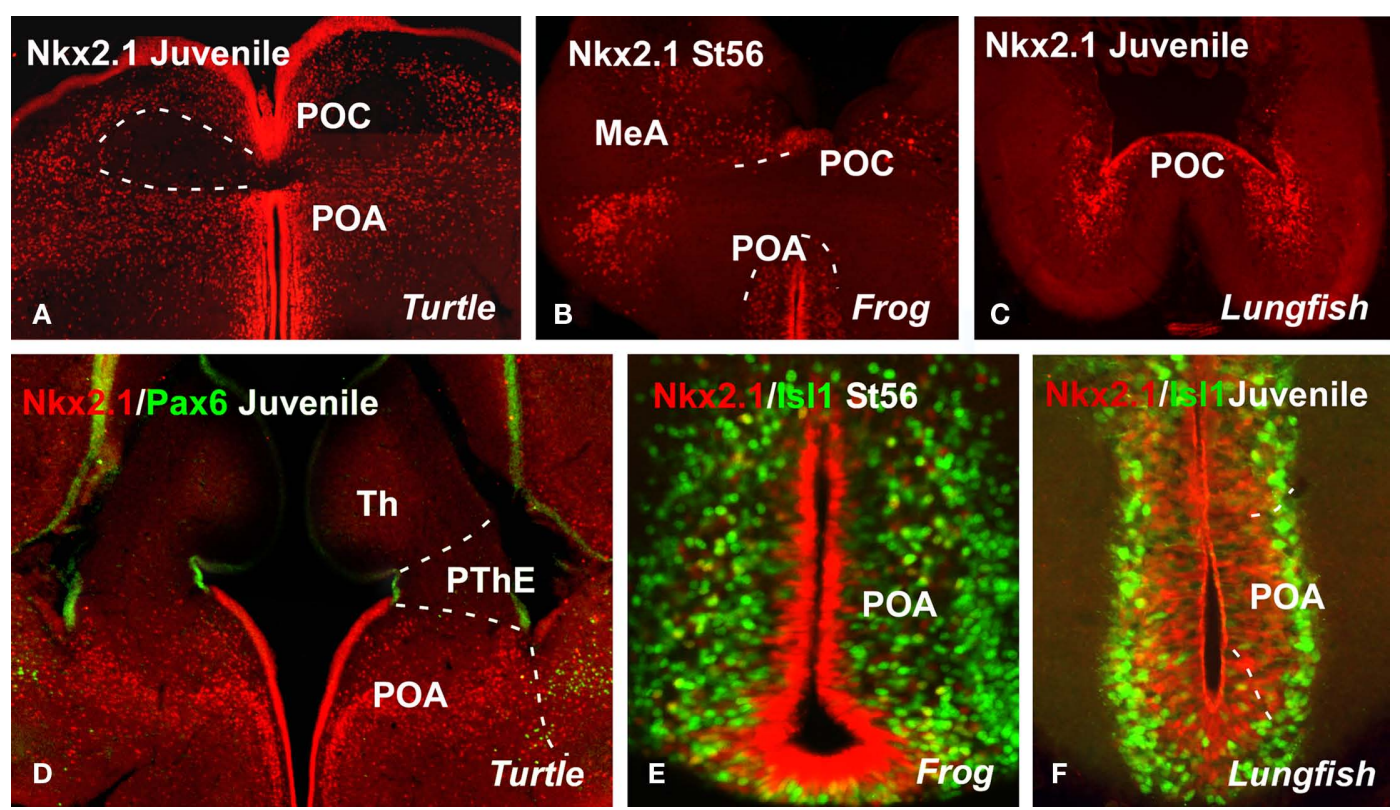

FIGURE 2 | Comparative aspects of the preoptic region.

Photomicrographs of transverse sections through non-evaginated portion of the secondary prosencephalon of a turtle [Pseudemys scripta; (A,D)], a frog [Xenopus laevis; (B,E)], and a lungfish [Neoceratodus forsteri; (C,F)] illustrating by immunohistochemistry the developing expression of different transcription factors indicated in each figure. MeA, medial amygdala; POA, preoptic area; POC, commissural preoptic area; PThE, prethalamic eminence; Th, thalamus. 
of teleost fishes expressing Nkx2.1 is correlated with expression of Lhx6 and/or Lhx7/8 in the same domains, and the presence of pallidal-like cell groups as well as cholinergic cells resembling those of the corticopetal system (Pérez et al., 2000; Mueller et al., 2004; Wullimann and Mueller, 2004; Menuet et al., 2007). However, more data are needed to determine whether the preoptic part of the subpallium in other jawed fishes (such as zebrafish) includes subdivisions similar to those of tetrapods. In a strikingly different situation, the homolog of $\mathrm{Nkx} 2.1$ in lampreys (LjNkx2.1, and a putative homolog of Sonic hedgehog ( $\mathrm{LfHh}$ ) in gnathostomes have no expression domain in the ventral telencephalon in lampreys(Ogasawara et al., 2001; Murakami et al., 2005; Osorio et al., 2005). The forebrain expression pattern of $\mathrm{LfHh}$ comprises two separate domains, a small hypothalamic domain and a large and robust coma-shaped domain in the diencephalon, showing continuity with floor plate expression all along the neural tube.

The alar part of the hypothalamus (Figures 3A-F) has been said to contain the SPV area and the SC region. The SPV is a component of the central neural circuitry that regulates several homeostatic variables through numerous connections among others with the posterior pituitary. The homeodomain transcription factor Otp is particularly expressed in this region in mice, chicks, amphibians, and lungfishes (Figures 3A-C), allowing it to be distinguished from the Shh- Nkx2.1- Dlx-expressing adjacent domains (Bardet et al., 2008; Moreno et al., 2010). Other shared features of this region, at least shared among amniotes, include Pax6 ventricular expression (Flames et al., 2007; Moreno et al., 2010). The SPV region in Xenopus could differ a little from that described in amniotes because, among other peculiarities, it does not include Pax6 expressing cells (Moreno et al., 2008b). The zebrafish genome contains two Otp orthologs, expressed in almost identical forebrain domains (Del Giacco et al., 2006), largely comparable to the Otp-expressing zones in mice (Simeone et al., 1994). In lampreys there are no detailed data on Otp expression, however it has been reported that its hypothalamic distribution resembles that of the Otp-positive neurons in zebrafish (Joly et al., 2007). However, Pax6 expression has not been described in the hypothalamic region (Murakami et al., 2001).

In the case of the SC region (Figures 3D-F), it has been shown to be $D l x$-positive territory in all the vertebrates examined (Bachy et al., 2002; Brox et al., 2003; Flames et al., 2007; Domínguez et al., 2010). The expression of Nkx2.1, however, has been detected only in non-mammalian vertebrates (Bachy et al., 2002; Moreno et al., 2008a; van den Akker et al., 2008; Abellán and Medina, 2009; Domínguez et al., 2010; Moreno et al., 2010). This region of Nkx2.1 expression runs parallel to the hypothalamic zone of Shh expression, in a zone containing Arx- and Gad67-positive cells, and it is also defined by the expression of Lhx6, Lhx8, and Lhx1. In Xenopus,
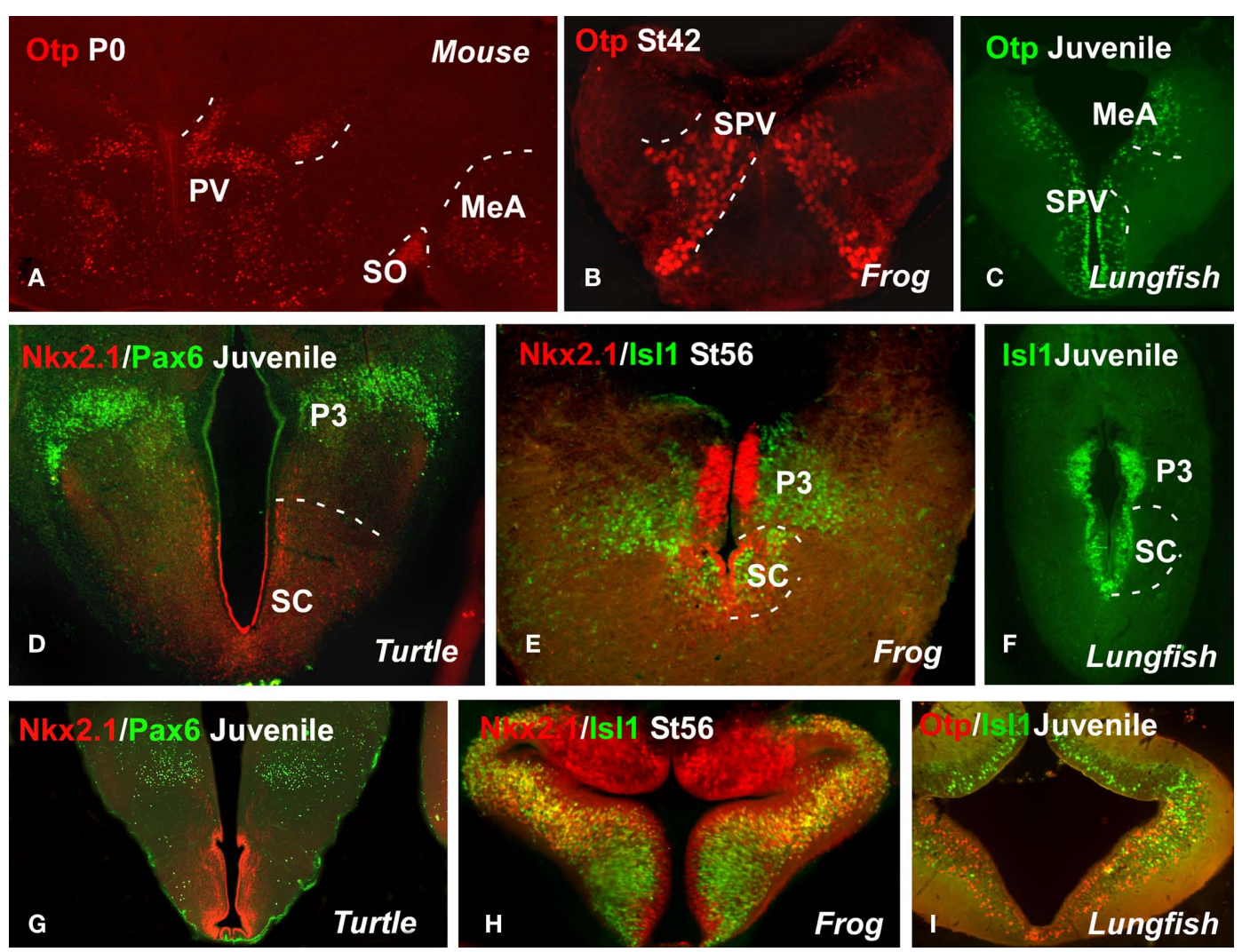

FIGURE 3 | Comparative aspects of the hypothalamus. Photomicrographs of transverse sections through non-evaginated portion of the secondary prosencephalon of a mouse (A), a turtle [Pseudemys scripta; (D,G)], a frog [Xenopus laevis; (B,E,H)], and two lungfishes [Neoceratodus forsteri; (C,F) and
Protopterus dolloi; (I)] illustrating by immunohistochemistry the developing expression of different transcription factors indicated in each figure. MeA, medial amygdala; P3, prosomere 3; PV, paraventricular nuclei; SO, supraoptic nuclei; SC, suprachiasmatic area; SPV, supraopticparaventricular area. 
Isl1, $x$ Lhx1, and $x L h x 5$ expression has been described as restricted to the SC area (Moreno et al., 2004, 2008a). Some distinction was noted in distribution, as the cells located just above and rostral to the optic chiasm only expressed xLhx1, whereas more caudally in the SC nucleus two regions could be distinguished: a dorsal portion that only expressed $x \operatorname{Lhx} 5$ and a ventral portion that expressed both xLhx1 and xLhx5 (Moreno et al., 2004).

In regard to the basal hypothalamus, the ventral tuberomammillary cells in chick embryogenesis arise from a set of floor plate-like precursors that initially express Shh (Manning et al., 2006). The transcription factor Tbx 2 is expressed only transiently in the mammillary region, for a slightly longer period in the tuberal region, and it is retained only at the junction of the retrochiasmic/tuberal hypothalamus (Manning et al., 2006). In the tuberal hypothalamus of Pseudemy scripta (Moreno et al., 2010), X. laevis (Moreno et al., 2008a; Domínguez et al., 2010), and the two lungfishes (unpublished observations) it was observed that the Nkx2.1 expression is strong in the $\mathrm{vz}$ of the tuberal area, whereas Isl1 is restricted to the svz; and the expression of Otp is restricted to the arcuate nucleus (Figure 3I). In Xenopus, xShh expression is strong in the basal hypothalamus, specifically in the mammillary band and the tuberal area. This expression is mainly restricted to the anterior levels, and xShh expression was not detected in the most posterior basal hypothalamic levels (Domínguez et al., 2010). The basal hypothalamus contains some populations of xGAD67- and xDll-4-expressing cells (Brox et al., 2003). The relatively few cells that express $x L h x 7$ in the mammillary region in adults could be distinguished in the caudal hypothalamus from early premetamorphic stages (Moreno et al., 2004). The dorsomedial hypothalamic area and the superficial mammillary and mammillary nuclei contained a small to moderate number of xGAD67-expressing perikarya.

\section{CONCLUDING REMARKS: EVOLUTIONARY HYPOTHESIS}

The main conclusion of this comparative study is that major histogenetic processes thought to be a hallmark of so-called "higher vertebrates" actually existed early in vertebrate phylogeny (summarized in Figure 4).

At anterior levels in the PO, lampreys (jawless fish) lack expression of Nkx2.1 in the basal telencephalon (Murakami et al., 2001), and this is correlated with the absence of Shh expression (Osorio et al., 2005). This suggests that the subpallium of the first vertebrates not only lacked a pallidal domain (as noted above), but also appear to have lacked a subdivision comparable to the preoptic subpallium (for review see Osorio and Rétaux, 2008). This would correlate with the apparent lack of both pallidal-like cells (like those of the pallidal part of the basal ganglia) and basal forebrain cholinergic cells (Pombal et al., 1997a,b, 2001) in the telencephalon of lampreys. In teleosts, the detection of both Shh and Dlx expression shows that Shh expression can be localized in the basal telencephalon/POA at late developmental stages (Scholpp et al., 2006; Menuet et al., 2007). A pallidum expressing Nkx2.1 and a POC region comparable to that in amphibians have been demonstrated in the telencephalon of lungfishes (González and Northcutt, 2009), although the presence of Shh expression in the telencephalon needs to be investigated. Therefore, based on those lack of Nkx2.1 and Shh expression in lampreys (Osorio et al., 2005) and the organization of the POA demonstrated in amphibians (Moreno et al., 2008a; Domínguez

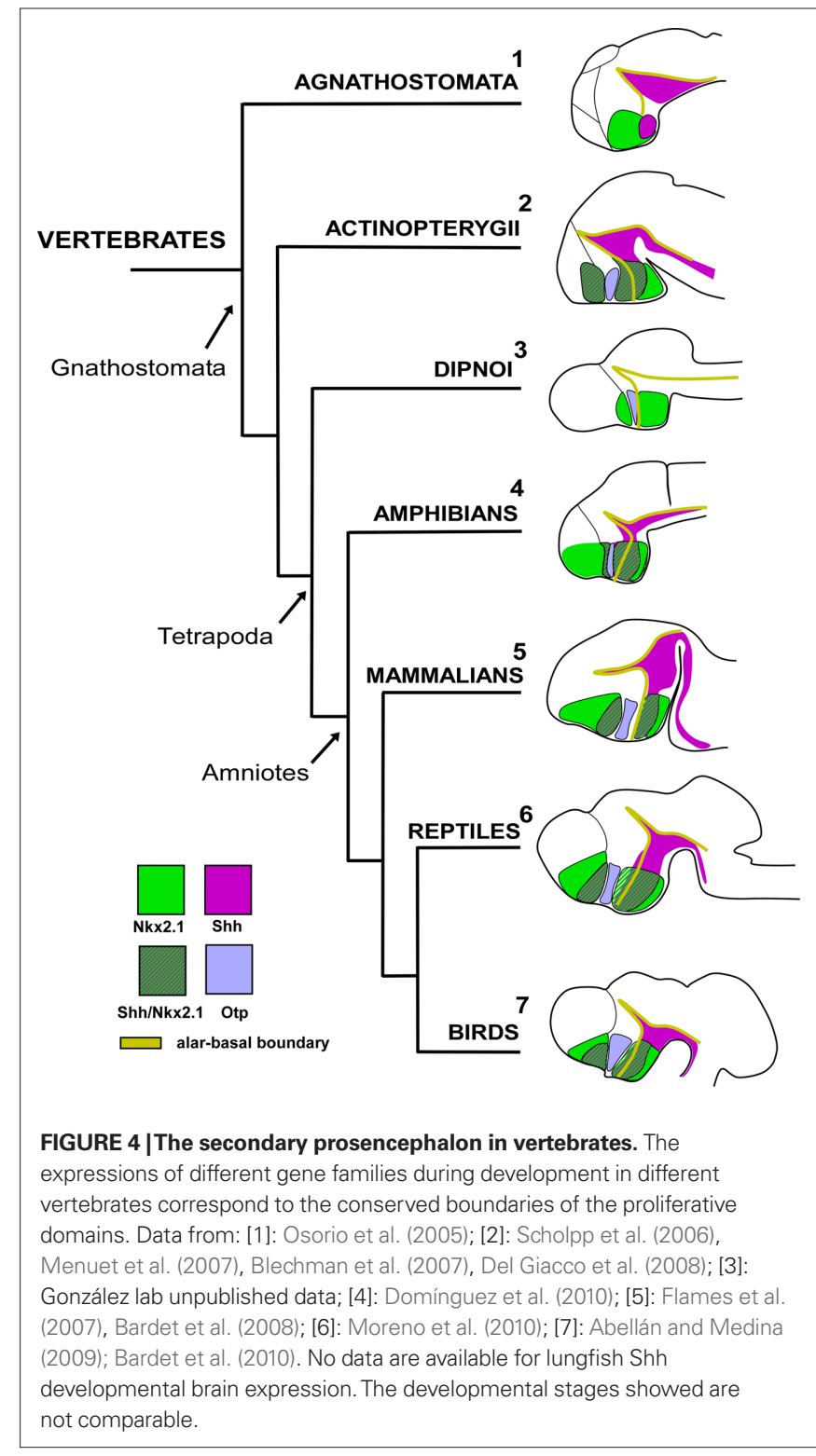

et al., 2010) it can be postulated that the de novo expression of Shh and Nkx2.1 in the basal telencephalon of gnathostomes may be responsible for the emergence of new brain structures in the subpallium, the pallidum, and the PO, which probably emerged in the transition from agnathans to gnathostomes (see also Murakami et al., 2005; Osorio and Rétaux, 2008).

In the alar hypothalamus, the first thing to consider is the presence of the SPV throughout vertebrates. In all groups examined, this area expresses Otp and lacks Nkx2.1/Shh/Dlx, in a very conserved pattern (reviewed in Medina, 2008). In addition, the maintenance of Otp expression throughout development seems to be a conserved feature in vertebrates, as inferred from the cases in which late developmental stages or adult specimens were studied. It is noteworthy that Otp-expressing cells were consistently noted in some subdivisions of the amygdala (Bardet et al., 2008; Moreno et al., 2010), subdivisions whose cells most likely have a hypothalamic origin (Soma et al., 2009). At present, there are no 
anatomical data regarding possible Otp expression in the amygdala in teleosts or lampreys, but given the Otp expression found in the amygdala in adult lungfish (González and Northcutt, 2009) it will be an interesting aspect to investigate, in the context of evolution of the amygdaloid complex.

Finally, in amniotes the hypothalamic area lacking Nkx2.1 expresses Pax6. It is possible that the double Nkx2.1/Pax6 expression is an exclusive feature of the forebrain of anamniotes, not only present in the pallium but also in the hypothalamus. Consistent with this idea is the finding that, in mice, the absence of $\mathrm{Nkx} 2.1$ expression in the alar hypothalamus correlates with expression of Pax6 in the whole alar diencephalon, including the alar hypothalamus (Puelles et al., 2000; Marín et al., 2002). Thus, the mutually exclusive balance between $\mathrm{Nkx} 2.1$ and Pax6 in the telencephalon and diencephalon may be important for the relative size of pallial versus subpallial and thalamic versus hypothalamic territories. Any alteration of this balance, as occurs in Nkx2.1 knockout mice and Nkx2.1 knockdown Xenopus Sussel et al., 1999; Marín et al., 2002; van den Akker et al., 2008) or in Pax6 knockout mice (Stoykova et al., 2000; Yun et al., 2001), modifies the relative size of these subdivisions.

In the case of the SC region, the phylogenetic diagram in Figure 4 shows the expression of the orthologous homeobox gene Nkx2.1 in several vertebrate species, including a jawless

\section{REFERENCES}

Abellán, A., and Medina, L. (2009). Subdivisions and derivatives of the chicken subpallium based on expression of LIM and other regulatory genes and markers of neuron subpopulations during development. J. Comp. Neurol. 515, 465-501.

Acampora, D., Postiglione, M. P., Avantaggiato, V., Di Bonito, M., Vaccarino, F. M., Michaud, J., and Simeone, A. (1999). Progressive impairment of developing neuroendocrine cell lineages in the hypothalamus of mice lacking the orthopedia gene. Genes Dev. 13, 2787-2800.

Bachy, I., Failli, V., and Rétaux, S. (2002). A LIM-homeodomain code for development and evolution of forebrain connectivity. Neuroreport 13, A23-A27.

Bachy, I., Vernier, P., and Retáux, S. (2001). The LIM-homeodomain gene family in the developing Xenopus brain: conservation and divergences with the mouse related to the evolution of the forebrain. J. Neurosci. 21, 7620-7629.

Bardet, S. M., Cobos, I., Puelles, E., Martínez-De-La-Torre, M., and Puelles, L. (2006). Chicken lateral septal organ and other circumventricular organs form in a striatal subdomain abutting the molecular striatopallidal border. J. Comp. Neurol. 499, 745-767.

Bardet, S. M., Ferran, J. L., SánchezArrones, L., and Puelles, L. (2010). Ontogenetic expression of sonic hedgehog in the chicken subpallium.

fish (a lamprey), a jawed fish (a zebrafish), an amphibian (a frog), a reptile (a turtle), a bird (a chicken), and a mammal (a mouse). This comparative representation highlights the peculiar lack of expression in this region only in the case of the forebrain of mammals. Considering the expression patterns observed in chicks and mice (Shimamura et al., 1995; Puelles et al., 2000), it appears that the alar hypothalamic expression of $\mathrm{Nkx} 2.1$ was either dramatically reduced or disappeared during the evolution to birds and mammals (Medina, 2008; van den Akker et al., 2008), a trend that perhaps started during the anamniote-amniote transition. Analysis of the xNkx2.1 knockdown Xenopus embryos indicates that $\mathrm{xNkx} 2.1$ controls the relative size of major regions in both the telencephalon (subpallium versus pallium) and the diencephalon (thalamus versus hypothalamus) of the forebrain (van den Akker et al., 2008). Changes in the regulation of Nkx2.1 expression have played an important role in the evolution of forebrain development, and they emphasize the potential of combined analysis of expression and function of master control genes in different vertebrates for revealing the origins of brain complexity and diversity.

\section{ACKNOWLEDGMENTS}

This work supported by grants from Spanish MICINN and the UCM (Grant numbers: BFU2009-12315 and BSCH-UCM GR58/08).

Bruce, L. L. (2008). "Evolution of the hypothalamus in amniotes," in Encyclopedic Reference of Neuroscience, eds M. D. Binder and N. Hirokawa (Springer-Verlag), 1363-1367.

Butler, A., and Hodos, W. (2005). Comparative Vertebrate Neuroanatomy. Hoboken, NJ: Wiley.

Chiang, C., Litingtung, Y., Lee, E., Young K. E., Corden, J. L., Westphal, H., and Beachy, P. A. (1996). Cyclopia and defective axial patterning in mice lacking sonic hedgehog gene function. Nature 383, 407-413.

Clack, J. A. (2002). Patterns and processes in the early evolution of the tetrapod ear. J. Neurobiol. 53, 251-264.

Couly, G. F., and Le Douarin, N. M. (1987). Mapping of the early neural primordium in quail-chick chimeras. II. The prosencephalic neural plate and neural folds: implications for the genesis of cephalic human congenital abnormalities. Dev. Biol. 120, 198-214.

Davis, A. M., Seney, M. L., Stallings, N. R., Zhao, L., Parker, K. L., and Tobet, S. A. (2004). Loss of steroidogenic factor 1 alters cellular topography in the mouse ventromedial nucleus of the hypothalamus. J. Neurobiol. 60, 424-436.

Del Giacco, L., Pistocchi, A., Cotelli, F., Fortunato, A. E., and Sordino, P. (2008). A peek inside the neurosecretory brain through Orthopedia lenses. Dev. Dyn. 237, 2295-2303.

Del Giacco, L., Sordino, P., Pistocchi, A., Andreakis, N., Tarallo, R., Di
Benedetto, B., and Cotelli, F. (2006). Differential regulation of the zebrafish orthopedia 1 gene during fate determination of diencephalic neurons. BMC Dev. Biol. 6, 50. doi: 10.1186/1471-213X-6-50

Domínguez, L., González, A., and Moreno, N. (2010). Sonic hedgehog expression during Xenopus laevis forebrain development. Brain Res. 1347, 19-32.

Eagleson, G. W., and Harris, W. A. (1990). Mapping of the presumptive brain regions in the neural plate of Xenopus laevis. J. Neurobiol. 21, 427-440.

Eaton, J. L., and Glasgow, E. (2007). Zebrafish orthopedia (otp) is required for isotocin cell development. Dev. Genes Evol. 217, 149-158.

Eaton, J. L., Holmqvist, B., and Glasgow, E. (2008). Ontogeny of vasotocinexpressing cells in zebrafish: selective requirement for the transcriptional regulators orthopedia and singleminded 1 in the preoptic area. Dev. Dyn. 237, 995-1005.

Flames, N., Pla, R., Gelman, D. M., Rubenstein, J. L., Puelles, L., and Marín, O. (2007). Delineation of multiple subpallial progenitor domains by the combinatorial expression of transcriptional codes. J. Neurosci. 27, 9682-9695.

García-López, M., Abellán, A., Legaz, I., Rubenstein, J. L., Puelles, L., and Medina, L. (2008). Histogenetic compartments of the mouse centromedial and extended amygdala based on gene 
expression patterns during development. J. Comp. Neurol. 506, 46-74.

García-López, R., Pombero, A., and Martínez, S. (2009). Fate map of the chick embryo neural tube. Dev. Growth Differ. 51, 145-165.

González, A., López, J. M., and Marín, O. (2002a). Expression pattern of the homeobox protein NKX2-1 in the developing Xenopus forebrain. Brain Res. Gene Expr. Patterns 1, 181-185.

González, A., López, J. M., SánchezCamacho, C., and Marín, O. (2002b). Regional expression of the homeobox gene NKX2-1 defines pallidal and interneuronal populations in the basal ganglia of amphibians. Neuroscience $114,567-575$.

González,A., and Northcutt, R. G. (2009). An immunohistochemical approach to lungfish telencephalic organization. Brain Behav. Evol. 74, 43-55.

Goshu, E., Jin, H., Lovejoy, J., Marion, J. F., Michaud, J. L., and Fan, C. M. (2004). $\operatorname{Sim} 2$ contributes to neuroendocrine hormone gene expression in the anterior hypothalamus. Mol. Endocrinol. $18,1251-1262$.

Hallstrom, B. M., and Janke, A. (2009). Gnathostome phylogenomics utilizing lungfish EST sequences. Mol. Biol. Evol. 26, 463-471.

Hedges, S. B., Hass, C. A., and Maxson, L. R. (1993). Relations of fish and tetrapods. Nature 363, 501-502.

Hodos, W. (2008). "Evolution of the hypothalamus in anamniotes," in Encyclopedic Reference of Neuroscience, eds M. D. Binder and N. Hirokawa (Springer-Verlag), 1361-1363.

Inoue, T., Nakamura, S., and Osumi, N. (2000). Fate mapping of the mouse prosencephalic neural plate. Dev. Biol. 219, 373-383.

Joly, J. S., Osorio, J., Alunni, A., Auger, H., Kano, S., and Rétaux, S. (2007). Windows of the brain: towards a developmental biology of circumventricular and other neurohemal organs. Semin. Cell Dev. Biol. 18, 512-524.

Kimura, S., Hara, Y., Pineau, T., FernándezSalguero, P., Fox, C. H., Ward, J. M., and González, F. J. (1996). The T/ebp null mouse: thyroid-specific enhancer-binding protein is essential for the organogenesis of the thyroid, lung, ventral forebrain, and pituitary. Genes Dev. 10, 60-69.

Kuratani, S., Kuraku, S., and Murakami, Y. (2002). Lamprey as an evo-devo model: lessons from comparative embryology and molecular phylogenetics. Genesis 34, 175-183.

Labosky, P. A., Winnier, G. E., Jetton, T. L., Hargett, L., Ryan, A. K., Rosenfeld, M. G., Parlow, A. F., and Hogan, B. L. (1997). The winged helix gene, Mf3, is required for normal development of the diencephalon and midbrain, postnatal growth and the milk-ejection reflex. Development 124, 1263-1274.

Manning, L., Ohyama, K., Saeger, B., Hatano, O., Wilson S. A., Logan, M., and Placzek, M. (2006). Regional morphogenesis in the hypothalamus: a BMP-Tbx2 pathway coordinates fate and proliferation through Shh downregulation. Dev. Cell 11, 873-885.

Marín, O., Baker, J., Puelles, L., and Rubenstein, J. L. (2002). Patterning of the basal telencephalon and hypothalamus is essential for guidance of cortical projections. Development 129,761-773.

Marín, O., Smeets, W. J., and González, A. (1998). Evolution of the basal ganglia in tetrapods: a new perspective based on recent studies in amphibians. Trends Neurosci. 21, 487-494.

Medina, L. (2008). "Evolution and embryological development of forebrain," in Encyclopedic Reference of Neuroscience, eds M. D. Binder and N. Hirokawa (Springer-Verlag), 1172-1192.

Menuet, A., Alunni, A., Joly, J. S., Jeffery, W.R., and Rétaux, S. (2007). Expanded expression of sonic hedgehog in astyanax cavefish: multiple consequences on forebrain development and evolution. Development 134, 845-855.

Meyer, A., and Dolven, S. I. (1992). Molecules, fossils, and the origin of tetrapods. J. Mol. Evol. 35, 102-113.

Meyer, A., and Wilson, A. C. (1990). Origin of tetrapods inferred from their mitochondrial DNA affiliation to lungfish. J. Mol. Evol. 31, 359-364.

Michaud, J.L. (2001). The developmental program of the hypothalamus and its disorders. Clin. Genet. 60, 255-263.

Michaud, J. L., Rosenquist, T., May, N. R., and Fan, C. M. (1998). Development of neuroendocrine lineages requires the bHLH-PAS transcription factor SIM1. Genes Dev. 12, 3264-3275.

Moreno, N., Bachy, I., Rétaux, S., and González, A. (2004). LIMhomeodomain genes as developmental and adult genetic markers of Xenopus forebrain functional subdivisions. J. Comp. Neurol. 472, 52-72.

Moreno, N., Bachy, I., Rétaux, S., and González, A. (2005). LIMhomeodomain genes as territory markers in the brainstem of adult and developing Xenopus laevis. J. Comp. Neurol. 485, 240-254.

Moreno, N., Domínguez, L., Rétaux, S., and González, A. (2008a). Isletl as a marker of subdivisions and cell types in the developing forebrain of Xenopus. Neuroscience 154, 1423-1439.

Moreno, N., Rétaux, S., and González, A. (2008b). Spatio-temporal expression of Pax6 in Xenopus forebrain. Brain Res. 1239, 92-99.
Moreno, N., González, A., and Rétaux, S. (2009). Development and evolution of the subpallium. Semin. Cell Dev. Biol. 20, 735-743.

Moreno, N., Morona, R., López, J.M., and González, A. (2010). Subdivisions of the turtle Pseudemys scripta subpallium based on the expression of regulatory genes and neuronal markers. $J$. Comp. Neurol. 518, 4877-4902.

Mueller, T., Vernier, P., and Wullimann, $M$ F. (2004). The adult central nervous cholinergic system of a neurogenetic model animal, the zebrafish Danio rerio. Brain Res. 1011, 156-169.

Murakami, Y., Ogasawara, M., Sugahara, F., Hirano, S., Satoh, N., and Kuratani, S. (2001). Identification and expression of the lamprey Pax6 gene: evolutionary origin of the segmented brain of vertebrates. Development 128, 3521-3531.

Murakami, Y., Uchida, K., Rijli, F. M., and Kuratani, S. (2005). Evolution of the brain developmental plan: insights from agnathans. Dev. Biol. 280, 249-259.

Northcutt, R.G. (1970). The Telencephalon of the Western Painted Turtle (Chrysemys picta bellis). Chicago: University of Illinois Press.

Ogasawara, M., Shigetani, Y., Suzuki, S. Kuratani, S., and Satoh, N. (2001). Expression of thyroid transcription factor-1 (TTF-1) gene in the ventral forebrain and endostyle of the agnathan vertebrate, Lampetra japonica. Genesis 30, 51-58.

Osorio, J., Mazan, S., and Rétaux, S. (2005). Organisation of the lamprey (Lampetrafluviatilis) embryonic brain: insights from LIM-homeodomain, pax and hedgehog genes. Dev. Biol. 288, 100-112.

Osorio, J., Megias, M., Pombal, M. A., and Rétaux, S. (2006). Dynamic expression of the LIM-homeodomain gene Lhx15 through larval brain development of the sea lamprey (Petromyzon marinus). Gene Expr. Patterns 6, 873-878.

Osorio, J., and Rétaux, S. (2008). The lamprey in evolutionary studies. Dev. Genes Evol. 218, 221-235.

Pérez, S. E., Yañez, J., Marín, O., Anadón, R., González, A., and RodríguezMoldes, I. (2000). Distribution of choline acetyltransferase (ChAT) immunoreactivity in the brain of the adult trout and tract-tracing observations on the connections of the nuclei of the isthmus. J. Comp. Neurol. 428 450-474.

Pombal,M.A., El Manira, A., and Grillner, S. (1997a). Afferents of the lamprey striatum with special reference to the dopaminergic system: a combined tracing and immunohistochemical study. J. Comp. Neurol. 386, 71-91.
Pombal,M.A.,El Manira, A., and Grillner, S. (1997b). Organization of the lamprey striatum - transmitters and projections. Brain Res. 766, 249-254.

Pombal, M. A., Marín, O., and González, A. (2001). Distribution of choline acetyltransferase-immunoreactive structures in the lamprey brain. $J$. Comp. Neurol. 431, 105-126.

Price, M., Lazzaro, D., Pohl, T., Mattei, M. G., Ruther, U., Olivo, J. C., Duboule, D., and Di Lauro, R. (1992). Regional expression of the homeobox gene Nkx-2.2 in the developing mammalian forebrain. Neuron 8, 241-255.

Puelles, L., Kuwana, E., Puelles, E. Bulfone, A., Shimamura, K., Keleher, J., Smiga, S., and Rubenstein, J.L. (2000). Pallial and subpallial derivatives in the embryonic chick and mouse telencephalon, traced by the expression of the genes Dlx-2, Emx-1, Nkx-2.1, Pax-6, and Tbr-1. J. Comp. Neurol. 424, 409-438.

Puelles, L., and Rubenstein, J. L. (1993). Expression patterns of homeobox and other putative regulatory genes in the embryonic mouse forebrain suggest a neuromeric organization. Trends Neurosci. 16, 472-479.

Puelles, L., and Rubenstein, J. L. (2003). Forebrain gene expression domains and the evolving prosomeric model. Trends Neurosci. 26, 469-476.

Reiner, A., Medina, L., and Veenman, C. L. (1998). Structural and functional evolution of the basal ganglia in vertebrates. Brain Res. Brain Res. Rev. 28, 235-285.

Rétaux, S., Rogard, M., Bach, I., Failli, V., and Besson, M. J. (1999). Lhx9: a novel LIM-homeodomain gene expressed in the developing forebrain. J. Neurosci. 19, 783-793.

Rohr, K. B., Barth, K. A., Varga, Z. M., and Wilson, S. W. (2001). The nodal pathway acts upstream of hedgehog signaling to specify ventral telencephalic identity. Neuron 29, 341-351.

Roth, M., Bonev, B., Lindsay, J., Lea, R., Panagiotaki, N., Houart, C., and Papalopulu, N. (2010). FoxG1 and TLE2 act cooperatively to regulate ventral telencephalon formation. Development 137, 1553-1562.

Rubenstein, J. L., Shimamura, K., Martínez, S., and Puelles, L. (1998). Regionalization of the prosencephalic neural plate. Annu. Rev. Neurosci. 21, 445-477.

Ryu, S., Mahler, J., Acampora, D., Holzschuh, J., Erhardt, S., Omodei, D. Simeone, A., and Driever, W. (2007). Orthopedia homeodomain protein is essential for diencephalic dopaminergic neuron development. Curr. Biol. $17,873-880$. 
Sánchez-Arrones, L., Ferran, J. L., Rodríguez-Gallardo, L., and Puelles, L. (2009). Incipient forebrain boundaries traced by differential gene expression and fate mapping in the chick neural plate. Dev. Biol. 335, 43-65.

Scholpp, S., Wolf, O., Brand, M., and Lumsden, A. (2006). Hedgehog signalling from the zona limitans intrathalamica orchestrates patterning of the zebrafish diencephalon. Development $133,855-864$.

Schonemann, M. D., Ryan, A. K., McEvilly, R. J., O'Connell, S. M., Arias, C. A., Kalla, K. A., Li, P., Sawchenko, P.E., and Rosenfeld,M.G. (1995). Development and survival of the endocrine hypothalamus and posterior pituitary gland requires the neuronal POU domain factor Brn-2. Genes Dev. 9, 3122-3135.

Shimada, M., and Nakamura, T. (1973). Time of neuron origin in mouse hypothalamic nuclei. Exp. Neurol. 41, 163-173.

Shimamura, K., Hartigan, D. J., Martínez, S., Puelles, L., and Rubenstein, J. L. (1995). Longitudinal organization of the anterior neural plate and neural tube. Development 121, 3923-3933.

Shimogori, T., Lee, D. A., MirandaAngulo, A., Yang, Y., Wang, H., Jiang, L., Yoshida, A. C., Kataoka, A., Mashiko, H., Avetisyan, M., Qi, L., Qian, J., and Blackshaw, S. (2010). A genomic atlas of mouse hypothalamic development. Nat. Neurosci. 13, 767-775.

Simeone, A., D'Apice, M. R., Nigro, V., Casanova, J., Graziani, F., Acampora, D., and Avantaggiato, V. (1994). Orthopedia, a novel homeoboxcontaining gene expressed in the developing CNS of both mouse and Drosophila. Neuron 13, 83-101.
Soma, M., Aizawa, H., Ito, Y., Maekawa, M., Osumi, N., Nakahira, E., Okamoto, H., Tanaka, K., and Yuasa, S. (2009). Development of the mouse amygdala as revealed by enhanced green fluorescent protein gene transfer by means of in utero electroporation. J. Comp. Neurol. 513, 113-128.

Stoykova, A., Treichel, D., Hallonet, M., and Gruss, P. (2000). Pax6 modulates the dorsoventral patterning of the mammalian telencephalon. J. Neurosci. 20, 8042-8050.

Sussel, L., Marín, O., Kimura, S., and Rubenstein, J. L. (1999). Loss of Nkx2.1 homeobox gene function results in a ventral to dorsal molecular respecification within the basal telencephalon: evidence for a transformation of the pallidum into the striatum. Development 126, 3359-3370.

Szábo, N.E., Zhao, T., Cankaya, M., Theil, T., Zhou, X., and Alvarez-Bolado, G. (2009). Role of neuroepithelial Sonic hedgehog in hypothalamic patterning. J. Neurosci. 29, 6989-7002.

Takezaki, N., Figueroa, F., ZaleskaRutczynska, Z., Takahata, N., and Klein, J. (2004). The phylogenetic relationship of tetrapod, coelacanth, and lungfish revealed by the sequences of forty-four nuclear genes. Mol. Biol. Evol. 21, 1512-1524.

ten Donkelaar, H. J. (1998). "Anurans," in The Central Nervous System of Vertebrates. Urodela, Anura and Reptiles, eds R. Nieuwenhuys, H. J. ten Donkelaar, and C. Nicholson (London: Springer), 1145-1524.

Tohyama, Y., Ichimiya, T., KasamaYoshida, H., Cao, Y., Hasegawa, M., Kojima, H., Tamai, Y., and Kurihara,
T. (2000). Phylogenetic relation of lungfish indicated by the amino acid sequence of myelin DM20. Brain Res. Mol. Brain Res. 80, 256-259.

van den Akker, W. M., Brox, A., Puelles, L., Durston, A. J., and Medina, L. (2008). Comparative functional analysis provides evidence for a crucial role for the homeobox gene Nkx2.1/Titf-1 in forebrain evolution. J. Comp. Neurol. 506, 211-223.

Vieira, C., Pombero, A., García-López, R., Gimeno, L., Echevarria, D., and Martínez,S. (2010). Molecular mechanisms controlling brain development: an overview of neuroepithelial secondary organizers. Int. J. Dev. Biol. 54, 7-20.

Wang, W., and Lufkin, T. (2000). The murine Otp homeobox gene plays an essential role in the specification of neuronal cell lineages in the developing hypothalamus. Dev. Biol. 227, 432-449.

Wehr, R., Mansouri, A., de Maeyer, T., and Gruss, P. (1997). Fkh5-deficient mice show dysgenesis in the caudal midbrain and hypothalamic mammillary body. Development 124 , 4447-4456.

Wullimann, M. F., and Mueller, T. (2004) Teleostean and mammalian forebrains contrasted: evidence from genes to behavior. J. Comp. Neurol. 475 143-162.

Yun, K., Potter, S., and Rubenstein, J. L. (2001). Gsh2 and Pax6 play complementary roles in dorsoventral patterning of the mammalian telencephalon. Development 128, 193-205.

Zardoya, R., Cao, Y., Hasegawa, M., and Meyer, A. (1998). Searching for the closest living relative(s) of tetrapods through evolutionary analyses of mitochondrial and nuclear data. Mol. Biol. Evol. 15, 506-517.

Zardoya, R., and Meyer, A. (2001a). On the origin of and phylogenetic relationships among living amphibians. Proc. Natl. Acad. Sci. U.S.A. 98, 7380-7383.

Zardoya, R., and Meyer, A. (2001b). The evolutionary position of turtles revised. Naturwissenschaften 88 , 193-200.

Zhao, T., Szabo, N., Ma, J., Luo, L., Zhou, X., and Alvarez-Bolado, G. (2008). Genetic mapping of Foxb1-cell lineage shows migration from caudal diencephalon to telencephalon and lateral hypothalamus. Eur. J. Neurosci. 28, 1941-1955.

Conflict of Interest Statement: The authors declare that the research was conducted in the absence of any commercial or financial relationships that could be construed as a potential conflict of interest.

Received: 02 November 2010; paper pending published: 21 December 2010; accepted: 16 February 2011; published online: 02 March 2011.

Citation: Moreno Nand González A (2011) The non-evaginated secondary prosencephalon of vertebrates. Front. Neuroanat. 5:12. doi: 10.3389/fnana.2011.00012

Copyright $\odot 2011$ Moreno and González. This is an open-access article subject to an exclusive license agreement between the authors and Frontiers Media SA, which permits unrestricted use, distribution, and reproduction in any medium, provided the original authors and source are credited. 